\title{
Are regions equal in adversity? A spatial analysis of spread and dynamics of COVID-19 in Europe
}

\author{
Mounir Amdaoud ${ }^{1,3}$ (D) Giuseppe Arcuri ${ }^{2,3}$ (D) Nadine Levratto ${ }^{3}$ (i)
}

Received: 22 July 2020 / Accepted: 25 February 2021 / Published online: 22 March 2021

(c) The Author(s), under exclusive licence to Springer-Verlag GmbH Germany, part of Springer Nature 2021

\begin{abstract}
Often presented as a global pandemic spreading all over the world, COVID-19, however, hit not only countries but also regions differently. The objective of this paper is to focus on the spatial heterogeneity in the spread of the COVID-19 pandemic and to contribute to an understanding of the channels by which it spread, focusing on the regional socioeconomic dimension. For this, we use a dataset covering 125 European regions in 12 countries. Considering that the impact of the COVID-19 crisis differed sharply not only across countries but also across regions within the same country, the empirical strategy is based, on the one hand, on an exploratory analysis of spatial autocorrelations, which makes it possible to identify regional clusters of the disease. On the other hand, we use spatial regression models to capture the diffusion effect and the role of different families of regional factors in this process. We find that the share of older people in the population, GDP per capita, distance from achieving EU objectives, and the unemployment rate are correlated with high COVID-19 death rates. In contrast, the number of medical practitioners and hospital beds and the level of social trust are correlated with low COVID-19 death rates.
\end{abstract}

Keywords COVID-19 $\cdot$ EU regions $\cdot$ Social trust $\cdot$ Spatial models

JEL codes $\mathrm{C} 21 \cdot \mathrm{I} 14 \cdot \mathrm{R} 2$

\section{Introduction}

In the first months of 2020, COVID-19 affected many European countries and millions of people around the world. The pandemic required governments to operate in a context of radical uncertainty and to deal with difficult trade-offs given the health, economic and social challenges it raised.

After the first cases identified in Europe, different studies pointed out that European regions were not hit equally

Mounir Amdaoud

mounir.amdaoud@economix.fr

Giuseppe Arcuri

giuseppe.arcuri@univ-paris1.fr

Nadine Levratto

nadine.levratto@parisnanterre.fr

1 CEPN, CNRS, Université Paris Nord, Villetaneuse, France

2 PRISM, Université Paris 1 Panthéon-Sorbonne, Paris, France

3 EconomiX, CNRS, Université Paris Nanterre, Nanterre, France but that large differences existed between the peripheral regions where the infection rate remained limited and the core regions where the rates reached their maximum levels $[1,11]$.

The regional and local impacts of the COVID-19 crisis are highly heterogeneous, with a strong regional dimension that has important consequences for crisis management and policy responses. Governments at the subnational level are responsible for the crucial issues of containment measures, health care, social services, economic development and public investment, putting them at the frontline of crisis management [42].

COVID-19, like all pandemics, has a spatial dimension that needs to be considered [38]: the impact of the COVID19 crisis differs greatly not only across countries but also across regions and municipalities within countries, both in terms of declared cases and related deaths. In Italy, the country's north was the hardest hit, and one of the wealthiest regions in Europe, Lombardy, registered the highest number of cases. In France, the regions of Île-de-France and Grand Est were the most affected, whereas other regions 
were substantially untouched by the spread of the epidemic $[1,11]$.

The objective of this study is to contribute to an understanding of the channels by which the pandemic spread and to emphasize the regional socioeconomic dimension. This study contributes to the field of health geography, which underwent a profound renewal in the 1990s under the influence of numerous and varied research works in the fields of epidemiology, the environmental sciences, the social sciences, public health and service management to account for spatial disparities in terms of access to care, exposure to disease and morbidity [48]. This research also complements that undertaken by epidemiologists who point to individual factors, such as the age or health status of people affected by COVID-19 [44, 68].

There are a number of factors that contribute to the differential impact of COVID-19, which may also explain the disparities seen among European regions and countries. One factor relates to how the first "clusters" of cases developed. On many occasions, large cities, with their dense international links, are often the entry points for the virus and have been hit particularly hard [14].

Clinical data and surveillance, at an early stage, reported two important aspects of the pandemic: (i) the elderly male population (over the age of 65) and patients with comorbidities, such as diabetes, hypertension, chronic respiratory diseases, cancer and cardiovascular disorders are at higher risk of dying from COVID-19 [16] and (ii) there is a strong spatial dimension to the pandemic's spread $[1,11$, $28,40,42]$. Following this train of thought, a multitude of social and economic factors have been identified as potential determinants of the observed variety in COVID-19 outcomes. The importance of local socioeconomic parameters in explaining the health of populations and mortality rates has been widely demonstrated in the literature $[12,35]$. The Millennium Development Goals signed in September 2000 also underline the necessity of implementing social policies to improve the conditions of care to reduce mortality, especially for children. In addition, these factors have been associated with other epidemics in the past. For instance, Linard et al. [34] find that environmental and socioeconomic factors play a crucial role in determining the spatial variation in the Puumala and Lyme borreliosis infections in Belgium. Stanturf et al. [58] arrive at the same conclusion in their study on the 2014 Ebola epidemic in three West African countries (Liberia, Sierra Leone and Guinea). It follows that taking these contextual elements into account is essential for the study of health-related questions and that their omission would lead to a partial understanding of the phenomena studied, as underlined by Geronimus et al. [21] or, more recently and related to COVID-19 in Italy, by Bayer and Kuhn [7]. The latter, thus, envisage that family structures and the presence of families with several generations within the same dwelling differ according to region and could thus explain the geographic differences observed.

These socioeconomic factors that affect the occurrence and severity of an infectious disease can be grouped into four large categories: demographic determinants, income determinants, health care determinants and institutional determinants. Each captures an aspect of the local social environment.

Demography is a factor of spatial differentiation in health and, as such, is the subject of frequent analyses to explain international [27] and regional differences [20]. In their study on the European region, Sannigrahi et al. [53] find that the demographic composition of a country influences the rate of fatalities due to COVID-19. According to the WHO Regional Office for Europe (2020), 95\% of people who died from this novel pathogen in the European region were over 60 , and more than $50 \%$ of all deaths were among people aged 80 years or older. For Borjas [10] and Schmitt-Grohé et al. [54], demographics explain the spatial heterogeneity in COVID-19 testing and infection rates in New York City neighbourhoods. Population density has also been found to be crucial in controlling the spread of COVID-19. This result is confirmed by Amdaoud et al. [1] with French data and Bourdin et al. [11] with Italian data.

Wealth and income play a major role in driving the pattern of COVID-19 cases and deaths around the world. An important strand of literature has pointed out the role of poverty in the prevalence of cholera, as shown by Talavera and Perez [61] in an international comparison carried out using the data from the World Bank, and by Olson et al. [43] for tuberculosis. Occupations or the natures of jobs are likely to be determinants of infection, particularly those working in close physical proximity to other people (cleaners, retail staff, healthcare workers, teachers, etc.). Mongey et al. [40] showed that American workers in occupations that are more likely to be affected by social distancing policies are more economically vulnerable than other workers. These workers are less educated, less likely to have health insurance and are lower in the income distribution than workers in occupations that are unaffected by social distancing policies. Following Mathers and Schofield [37], we also consider unemployment, which has been shown to have significant harmful effects on morbidity and mortality. GDP per capita is another metric used in modelling health outcomes, health system performance and mortality trends $[36,60]$. This relationship is positive and significant in the case of COVID-19 [11]. Regions with a higher level of GDP per capita are at higher risk of viral transmission because of their increased social connections between individuals, resulting from higher levels of economic activity [19]. Moreover, in a connected and integrated world, rich regions are more open to international trade and the movement of people. Ascani et al. [5] suggest that the disease hit economic core locations harder. They 
argue that areas with a notable concentration of economic activities might be subject to a higher risk of population exposure due to the physical contact entailed by the agglomeration advantages in the local industries and to the spatiality of demand (internal and external local trade linkages) in the industries constituting the local economic structure. The quality of the health care system may also explain differences between regions [55], as is the case for diabetes [56] or COVID-19 in China [1]. For numerous countries in Europe, the local level is the relevant level for public health organizations. This line of reasoning clearly argues in favour of a geographic approach to COVID-19. In addition, on this subject, empirical studies report that first, well-structured healthcare resources positively affect a government's capacity to deal with public health emergencies, such as major epidemics [22, 69]. Second, healthcare infrastructures also have a considerable impact on the government's ability to rapidly detect, diagnose and report new infections [25, 26].

The institutional context, particularly regarding social institutions, is related to the behavioural and institutional response to the spread of COVID-19 infections. Managing the recent crisis between the different levels of government (local, national and supranational) is a central element highlighted by the OECD [42]. In a survey of social and behavioural results to support the COVID-19 pandemic response, Van Bavel et al. [62] highlight how most measures needed to contain an epidemic are, by their very nature, difficult to enforce directly: this, in turn, makes trust in public authorities and among citizens all the more relevant.

Thus, the negative impact of the COVID-19 pandemic can be mitigated by trust in institutions and among citizens, the basic component of social capital defined by Putnam [50] as "features of social organizations, such as networks, norms and social trust that facilitate coordination and cooperation for mutual benefit."

Possible mechanisms for building social trust for the adoption of health behaviours during a disease outbreak could be via community norms promoting a healthy lifestyle, the diffusion of health information, the promotion of access to local health services and cohesive social networks to provide affective support. This idea is corroborated in the recent work of Barrios et al. [6], which shows that a region's civic capital is at the origin of its collective capital, enabling human societies to improve policy actions from the government. After controlling for the severity of the COVID-19 pandemic, the authors show that areas with high civic capital report high degrees of voluntary compliance with public health recommendations (such as social distancing rules and mask wearing), both across U.S. counties and across European regions. Parallel to this, some studies have shown the significant role of social capital ${ }^{1}$ not only in the response and recovery stages after the health crisis but also regarding preparation and planning before a disaster even occurs [30]. This result is corroborated by Chuang et al. [13] for an influenza pandemic.

Thus, a key issue is to understand the potential impact of socioeconomic factors on the ongoing outbreak to support policy decisions pertaining to disease control. This is especially true for locations with a high incidence of COVID-19. In this context, this paper investigates the spreading power of COVID-19 in European regions and how this diffusion is related to those regions' socioeconomic characteristics. The evolution of the death rate in different European regions is quite similar over time and legitimates the choice of these dates to appreciate the kinetics of this epidemic. March $31^{\text {st }}$ corresponds to the take-off of the disease, April $30^{\text {th }}$ corresponds to the beginning of the slow down, and May $31^{\text {st }}$ marks the stabilization of the death rate. We propose the assumption that spatial dependence between regions across different channels explains the spatial heterogeneity in the spread of COVID-19.

In this study, we use a dataset covering 125 European regions (NUTS- 1 and NUTS-2) in 12 countries. The data on deaths from COVID-19 were collected for three crucial moments in the first wave of the pandemic: growth (March 31st), peak (April 30th) and decline (May 31st). The empirical strategy is based, on the one hand, on an exploratory analysis of the spatial autocorrelation, which makes it possible to account for the level of dependence in the death rate linked to COVID-19 for different places in space. On the other hand, we use spatial regression models to capture the diffusion effect and the role of different groups of factors in this process. Spatial and geostatistical techniques have been widely used in several studies dedicated to viruses, such as hepatitis $\mathrm{C}$ infections [29], MERS-CoV [33], H1N1 influenza [57], HIV [67], dengue [70] and recently, COVID-19 [1, 11, 28, 39].

The paper is organized as follows: we first discuss the data, the exploratory spatial data analysis (ESDA) and the econometric model; this is followed by a presentation of the empirical results. In the last section, we summarize the findings, discuss the study limitations, and suggest extensions for future research.

\footnotetext{
${ }^{1}$ Social capital is a complex notion, which includes various components such as trust, fairness and helpfulness, and social relations [46].
} 
Table 1 Definition of variables

\begin{tabular}{|c|c|c|c|}
\hline Variable & Definition & Year & Source \\
\hline COVID-19 death rate & $10,000 *$ (cumulative death toll due to COVID-19/population) & 2020 & $\begin{array}{l}\text { National ministries of } \\
\text { health and statistical } \\
\text { agencies }\end{array}$ \\
\hline Population density & Total population per $\mathrm{km}^{2}(\log )$ & 2019 & Eurostat \\
\hline Population concentration & Presence of one or more cities with $>1,000,000$ inhabitants & 2019 & Eurostat \\
\hline Share of the population aged 75 or over & Number of populations aged 75 or older over total population & 2019 & Eurostat \\
\hline GDP per capita & $\begin{array}{l}\text { Gross domestic product (GDP) per capita in Purchasing Power } \\
\text { Standards (PPS) }\end{array}$ & 2018 & Eurostat \\
\hline Unemployment rate & $\begin{array}{l}\text { Number of unemployed persons as a percentage of the labour } \\
\text { force }\end{array}$ & 2018 & Eurostat \\
\hline Distance to EU targets & $\begin{array}{l}\text { Index that estimates the distance of regions in relation to the } \\
\text { EU2020S headline targets }{ }^{\mathrm{a}}\end{array}$ & 2010 & ESPON \\
\hline General Medical Practitioners & $10,000 *$ (number of GPs/population) & 2017 & Eurostat \& NHS \\
\hline Hospital beds & $10,000 *($ number of hospital beds/population) & 2017 & Eurostat \& NHS \\
\hline Social trust & Index of social trust (see Appendix A1 for construction) & 2014-2016 & European Social Survey \\
\hline
\end{tabular}

${ }^{a}$ This index measures the distance that regions are from achieving these four targets: (i) early leavers from education and training, (ii) the share of population aged 30-34 with tertiary education, (iii) the percent of GDP invested in R\&D, and (iv) the employment rate for the population aged 20-65. A region would score 100 if it had reached all eight headline targets, whereas a region would score 0 if it was positioned the farthest away from all eight headline targets out of all regions in Europe. For more information about this index, see the SIESTA Final Scientific Report at https://www.espon.eu/programme/projects/espon-2013/applied-research/siesta-spatial-indicators-europe-2020-strategy

\section{Empirical framework}

\section{Data and variables}

This study covers 12 European countries. We chose NUTS-2 as the preferred regional level of analysis since NUTS-2 represents the basic region for the application of regional policies. Among the countries studied, four (Belgium, Germany, Ireland and the United Kingdom) do not have observations at the NUTS-2 level; therefore, we consider their NUTS-1 level regions. Therefore, we pool the observations into NUTS-1 and NUTS- 2 units to obtain a total sample of 125 regions. $^{2}$

The data on the explanatory variables entering the analysis are presented in Table 1 . The data are provided by different sources: Eurostat, the official database used for European Union (EU) regional studies and policy evaluations; ESPON (European Observation Network for Territorial Development and Cohesion); the NHS (United Kingdom National Health Service) and the European Social Survey. For each indicator, we consider the most recent data available.

On the basis of the literature discussed in Sect. 1, we distinguish four groups of indicators that may explain the spatial heterogeneity in mortality due to the COVID-19 pandemic: demographic and concentration determinants (population density, population concentration, the share of

\footnotetext{
2 The regions of Azores and Madeira in Portugal and the Canary Islands in Spain are excluded because of their geographical locations (far from the continent and geographically isolated).
}

the population aged 75 or over), income and wealth determinants (GDP per capita, the unemployment rate, distance to EU targets), health care determinants (general medical practitioners, hospital beds) and, finally, a composite index of social trust.

\section{Global and local spatial autocorrelation}

To test the existence of spatial clustering in the data, we applied the exploratory spatial data analysis method, which can provide useful summary information about the spatial arrangement of the mortality rates related to the COVID-19 pandemic. This approach has been employed in the literature to explain the geographic patterning of numerous phenomena [23]. The ESDA tools allow for the detection of global and local spatial autocorrelation. Global spatial autocorrelation, i.e. spatial dependency, has been employed to measure how each region's COVID-19 death rate compares with that of its neighbours and with that of more distant areas, giving an indication of the degree of spatial concentration in the pandemic across Europe. One of the most applied measures of global spatial autocorrelation is the $I$ coefficient developed by Moran [41]. Moran's I can be calculated as follows:

$$
I=\frac{n * \sum_{i}^{n} \sum_{j}^{n} W_{i j}\left(y_{i}-\bar{y}\right)\left(y_{j}-\bar{y}\right)}{\sum_{i}^{n} \sum_{j}^{n} W_{i j} \sum_{i}^{n}\left(y_{i}-\bar{y}\right)} .
$$

In Eq. (1), $n$ represents the number of spatial units indexed by $i$ and $j ; y$ is the variable of interest (the COVID-19 death 
rate in this study), $\bar{y}$ represents the mean of $y$; and $W_{i j}$ is an element of the spatial weight matrix. ${ }^{3}$ A randomized simulation procedure was used to estimate the significance of the coefficient $I$; the inference process is based on the permutation approach with 9,999 permutations. In this approach, Moran's $I$ is then computed for each of these randomized data values, and the observed value of $I$ is compared with the distribution of the $I$ values derived from the randomized data.

The LISA (local indicator of spatial association) proposed by Anselin [2] completes Moran's I by offering a more precise view of local spatial autocorrelation characteristics. LISA refers to the propensity of an area to group similar high or low values of $y$ or, on the contrary, very diverse values. It is calculated to evaluate the null hypothesis of a random distribution by comparing the values of each specific location with the values of neighbouring locations. The local version of Moran's I can be expressed as follows:

$I_{i}=z_{i} \sum_{j=1}^{n} w_{i j} z_{j} \quad j \neq i$

where $z_{i}$ is the difference in the variable $y$ in region $i$ from the global mean $\left(y_{i}-y\right), z_{j}$ is the difference in the variable $y$ in region $j$ from the global mean $\left(y_{j}-y\right)$, and $w_{i j}$ is an element in the $N \times N$ spatial weight matrix that for each observation (row), expresses those locations (columns) that belong to its neighbourhood set as nonzero elements. In this study, the specification of which elements are nonzero relies on the inverse of the distance weight function, such as $w_{i j}=1 / d_{i j}^{\alpha}$, where the effect of observation $j$ on $i$ is a declining function of the distance between them.

The same randomization method employed to assess the significance of the global Moran's I was used to determine the significance of the local measures of spatial autocorrelation (i.e. the forms of spatial associations).

The spatial distribution of the LISA coefficients distinguishes between five possible situations:

- High-high (HH) groupings or hotspots, where the spatial autocorrelation is positive such that spatial units with a high value of the variable are surrounded by similar spatial units,

- Low-low (LL) groupings or cold spots, where the spatial autocorrelation is also positive but, unlike the previous

\footnotetext{
3 The features of our sample containing islands imply that the use of a contiguity-based matrix is less appropriate. There are two additional arguments to justify this choice. First, the inverse distance form is supposed to be more informative and better performing in distinguishing between neighbouring and distant regions. Second, this matrix is commonly used to describe "distance-decay" behaviours [4]
}

grouping, is such that spatial units with a low value of the variable are surrounded by similar spatial units,

- Atypical groupings of the high-low (HL) type, where the spatial autocorrelation is negative in such a way that spatial units with a high value of the variable are surrounded by spatial units in which the variable has a low value,

- Atypical groupings of the low-high (LH) type, where the spatial autocorrelation is also negative but is such that spatial units with a low value of the variable are surrounded by spatial units in which the variable has a high value,

- Spatial units for which no significant spatial autocorrelation is found.

\section{Spatial regressive analysis}

In this subsection, we discuss our econometric model. For an easier understanding of regional disparities in mortality in Western Europe, it is crucial to highlight the different factors explaining those values. The econometric specification takes the linear ordinary least squares (OLS) regression model as a starting point:

$Y=X \beta+\varepsilon$,

$Y$ represents the dependent variable (the death rate due to COVID-19). $X$ represents the explanatory variables, $\beta$ is the vector of parameters to be estimated and $\varepsilon$ is the error term.

When spatial autocorrelation is ignored in the model specification but present in the data generating process, the OLS estimators are biased and not convergent. The first way to incorporate spatial autocorrelation into econometric models is through the spatial autoregressive model (SAR), which consists of correcting this bias by incorporating the spatially lagged dependent variable $Y$.

The model is written as follows:

$Y=\rho W Y+X \beta+\varepsilon$.

In Eq. (4), $W Y$ is the lagged dependent variable from the inverse distance matrix $W$, and $\rho$ is the autoregressive parameter indicating the intensity of the interaction between the observations of $Y$. In this model, the observed value of $Y$ is partly explained by the values taken by $Y$ in neighbouring regions. The introduction of the variable $W Y$ in the model above is a way to assess the degree of spatial dependence while the other variables are controlled for. On the other hand, it makes it possible to control for spatial dependence to assess the impact of the other explanatory variables. 


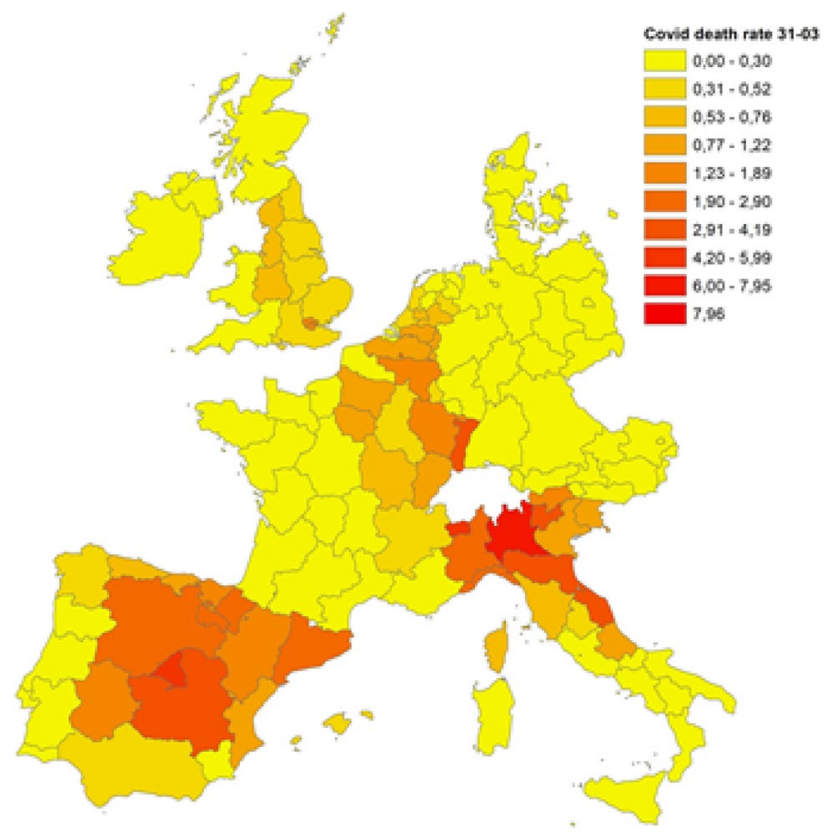

Fig. 1 COVID-19 death rates on March 31st, 2020. Source: Own elaboration on national ministries of health and statistical agencies datasets

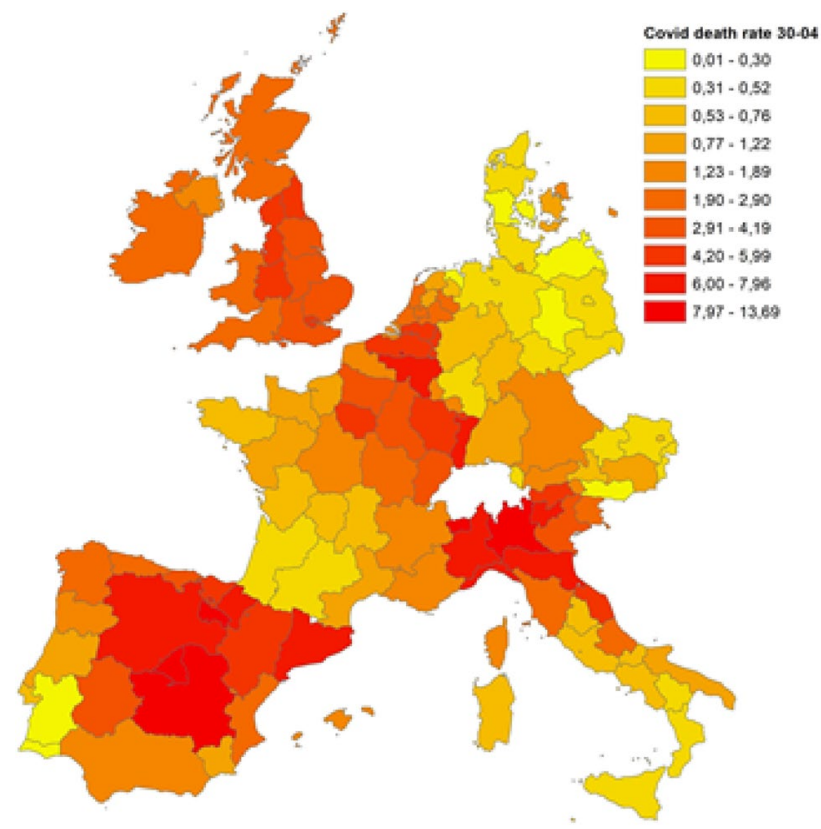

Fig. 2 COVID-19 death rates on April 30th, 2020. Source: Own elaboration on national ministries of health and statistical agencies datasets

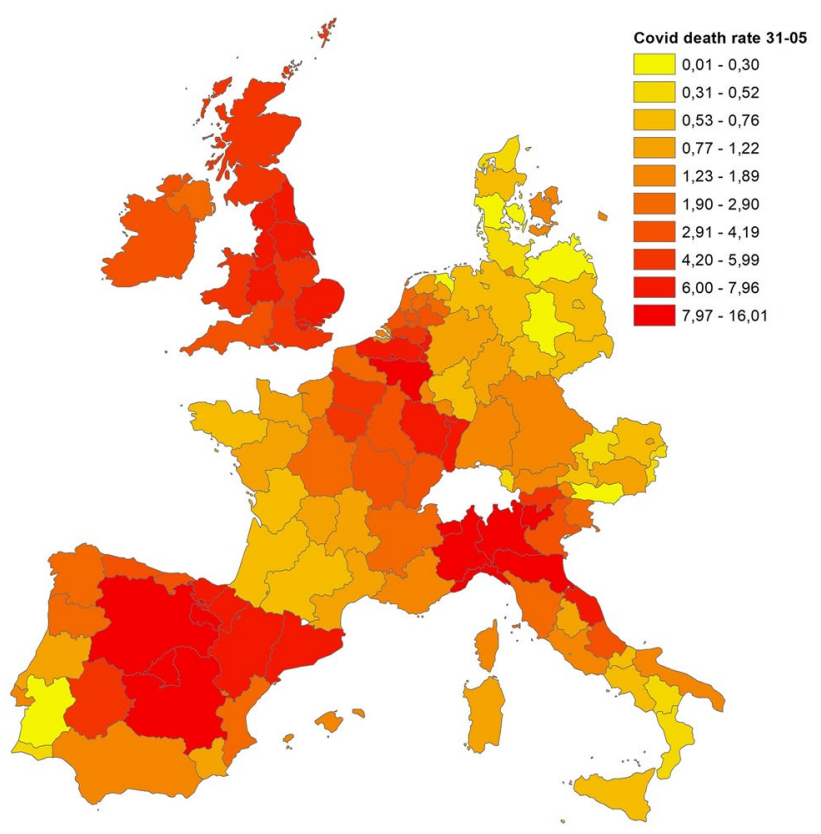

Fig. 3 COVID-19 death rate at May 31st 2020 Source: Own elaboration on National ministries of health and statistical agencies datasets

A second way to incorporate spatial autocorrelation into econometric models is the spatial error model (SEM) ${ }^{4}$ which consists of specifying a process of spatial dependence in the errors in a regression model. The SEM model is defined as follows:

$Y=X \beta+\varepsilon$ with $\varepsilon=\lambda W_{\epsilon}+u$,

The parameter $\lambda$ reflects the intensity of the interdependence between the residuals of the regression, and $u$ is the error term. Omitting the spatial autocorrelation in the errors produces unbiased, but inefficient estimators, so statistical inference based on OLS will be biased. According to Le Gallo [31], different approaches can be used for the choice of models. We adopted the so-called bottom-up approach, which consists of starting with the nonspatial model. The Lagrange multiplier test [3] then makes it possible to decide between the SAR, the SEM or a nonspatial model; in our case, the results suggest better performance from the SAR model. Furthermore, SAR results are the most appropriate model to capture, from an econometric point of view, the spread of epidemics across neighbouring regions. This model allows us to take into account spatial dependence in the explanatory variable and, in our case, the impact of the number of infected people spreading the virus between neighbouring regions. Accordingly, this model allows us to

\footnotetext{
${ }^{4}$ The modelling of both endogenous interaction effects on the one hand and interaction effects among the error terms on the other hand is due to the seminal contribution of Anselin [4].
} 
Table 2 Moran's I statistics

\begin{tabular}{llllll}
\hline Indicator & Morans' I & Mean & SD & Standardized value & $p$ value \\
\hline COVID-19 death rate on March 31st & 0.355 & -0.0083 & 0.0497 & 7.3018 & 0.0001 \\
COVID-19 death rate on April 30th & 0.384 & -0.0081 & 0.0519 & 7.5516 & 0.0001 \\
COVID-19 death rate on May 31st & 0.398 & -0.0084 & 0.0521 & 7.7994 & 0.0001 \\
\hline
\end{tabular}

Source: Own elaboration on national ministries of health and statistical agencies datasets

obtain estimators of the parameter $\rho$ that characterize the transmission effect [11].

\section{Results}

\section{Spatial dynamics of COVID-19 death rates}

The data on COVID-19-related deaths by region were collected from the dataset provided by the health ministries and national statistical offices of the countries included in this study. The indicator for pandemic diffusion used in this study is the COVID-19 death rate, defined as the cumulative number of COVID-19-related deaths registered in a region per 10,000 inhabitants. We collected this information at three different time points (March 31st, April 30th, May 31 st) to capture the temporal evolution of the pandemic.

Figures 1, 2 and 3 display the distribution of COVID-19 death rates across European regions at the three time points in our analysis. COVID-19, like all pandemics, has a spatial dimension that needs to be managed, and it is clear that the impact of the COVID-19 crisis may differ not only across countries but also across regions. At the end of March 2020, three countries were particularly affected by the epidemic: Italy, France and Spain. In Italy, the country's north was the hardest hit, and one of the wealthiest regions in Europe, Lombardy, registered the highest death rate (7.16 deaths per 10,000 inhabitants). High death rates were also registered in the Madrid region (Spain) and in Alsace (France), with 5.82 and 3.12 deaths per 10,000 inhabitants, respectively. In the following weeks, the COVID-19 epidemic spread throughout Europe, and at the end of April, higher death rates were registered in Italy (north), Spain (centre), France (Alsace and Lorraine), Belgium, the Netherlands and London. A similar picture comes from the analysis conducted for the end of May, with a higher diffusion in many regions of the United Kingdom, whereas Austria, Germany and Denmark were countries less hit by the pandemic, with $0.70,0.83$ and 0.87 deaths per 10,000 inhabitants, respectively.

\section{Global and local patterns of spatial concentration}

Diagnostics ofglobal and local spatial autocorrelation were carried out with the free and open-source software Geoda
1.18, developed by Luc Anselin and his team. ${ }^{5}$. The spatial patterns and spill-over characteristics are presented in the following text.

The generated Moran's I values (Table 2) are highly significant $(p$ value $<0.0001)$ and indicate a quite strong degree of positive spatial autocorrelation; regions with similar rates of COVID-19 deaths tend to be located next to each other (i.e. they form spatial clusters). Furthermore, there is little change over the three dates, with Moran's $I$ increasing over time. This trend is marginal, but it may suggest that the degree of spatial clustering in COVID-19 death rates may be growing.

To assess the level of spatial concentration in the COVID19 death rates, the local indicators of spatial association (LISA) [2] are used to complement this part of the analysis. In particular, the LISA maps identify clusters or collections of geographical units that are similar, in statistical terms, based on the pandemic indicator used. They are used to identify hotspots or cold spots across space. Hotspots are of particular interest in epidemiological analysis, such as of the spread of COVID-19, as they allow the identification of "hot" areas significantly affected by the virus.

Figures 4, 5 and 6 display the local indicators of spatial autocorrelation reported for the COVID-19 death rates between March and May $2020^{6}$ and reveal distinctive geographic patterning in the spread of the pandemic that is masked when assessing global indicators. Positive spatial autocorrelation is observed in areas labelled high-high (i.e. high death rates in a region surrounded by a high weighted average rate for the neighbouring regions) and low-low (a low rate in a region surrounded by a low weighted average rate for the neighbouring regions). There are also two forms of negative spatial associations (i.e. associations between regions with dissimilar values): high-low (a high rate in a region surrounded by a low weighted average rate for the neighbouring regions), and low-high (a low rate in a region surrounded by a high weighted average rate for the neighbouring regions).

Visually comparing the maps for each individual time point reveals some distinctive geographical patterning that remains mostly consistent over time: the north of Italy

\footnotetext{
5 Available at https://geodacenter.github.io/index.html

${ }^{6}$ We do not use methods to control for the false discovery rate (FDR) in this work.
} 


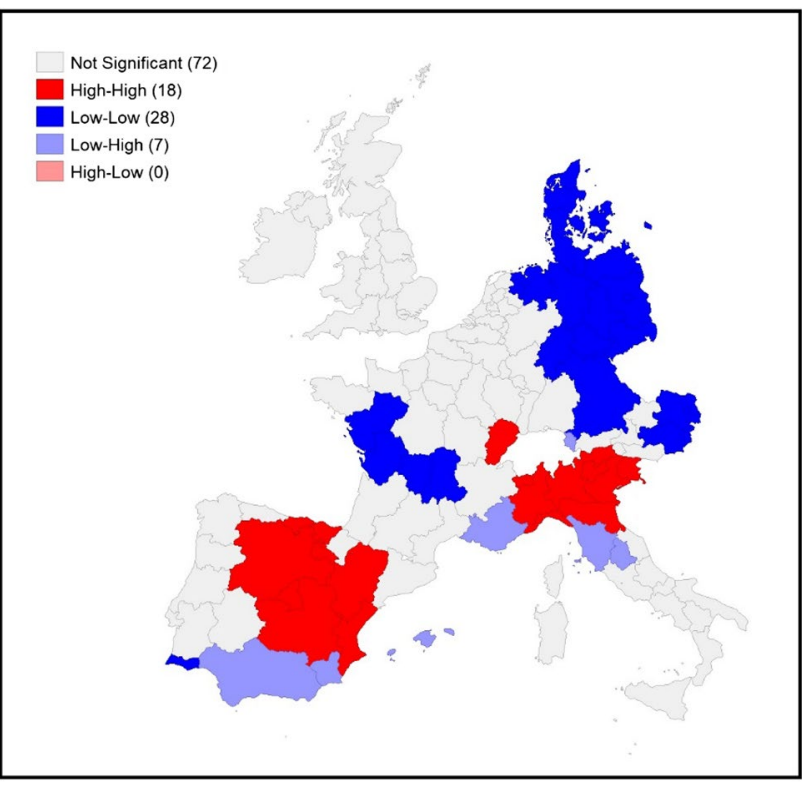

Fig. 4 LISA for COVID-19 death rates on March 31st, 2020. Source: Own elaboration on national ministries of health and statistical agencies datasets

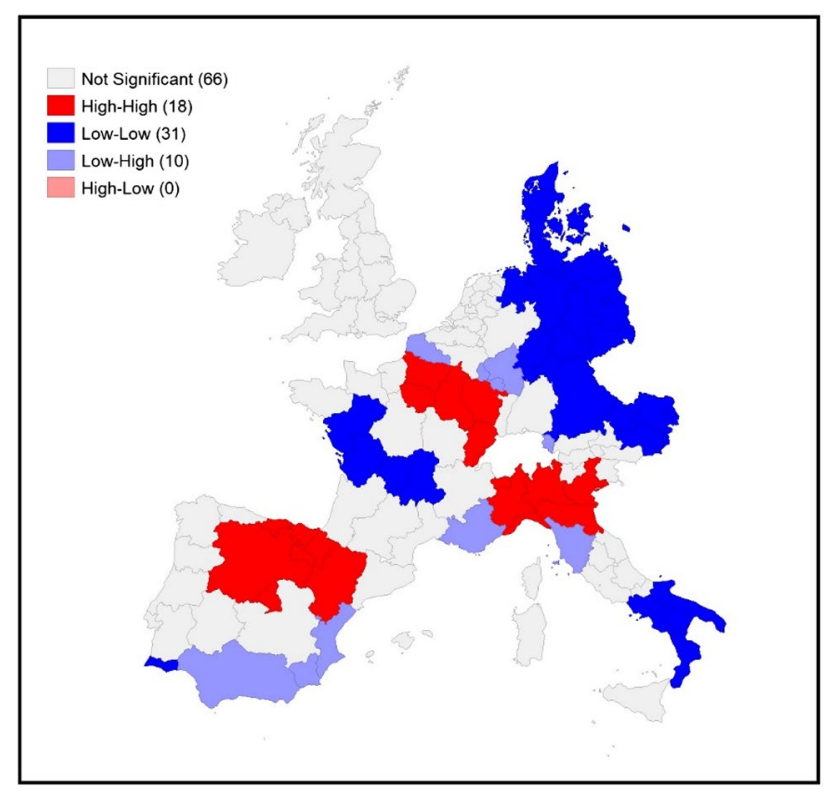

Fig. 5 LISA for COVID-19 death rates on April 30th, 2020. Source: Own elaboration on national ministries of health and statistical agencies datasets

(with a slight reduction in April and May) and the regions around Madrid have high-high clustering at all three time points. The high-high clustering recorded in France started in the region of France-Comté but rapidly spread into a

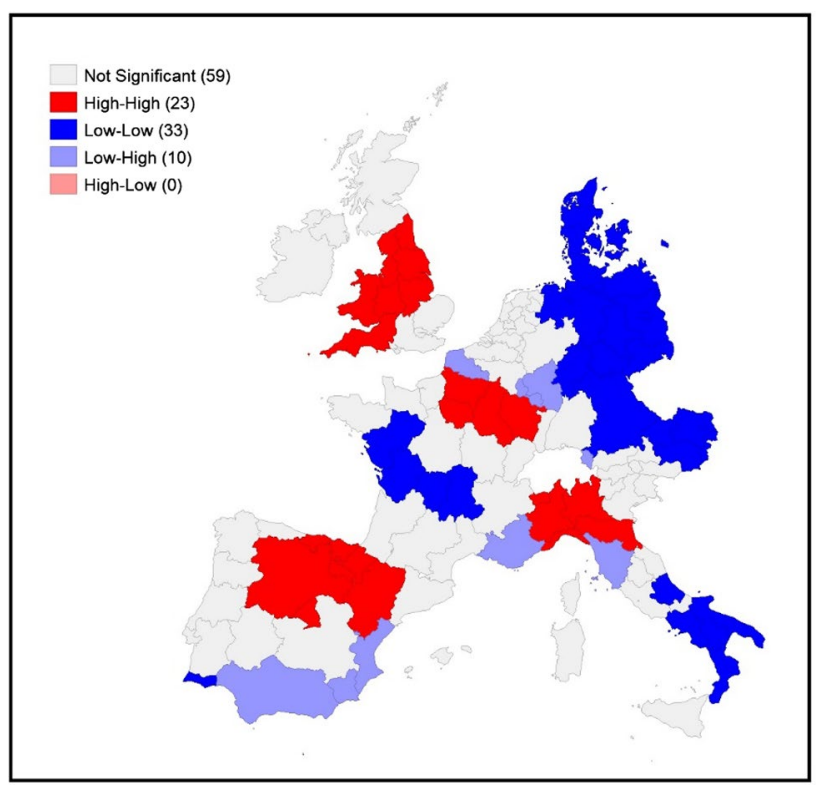

Fig. 6 LISA for COVID-19 death rates on May 31st, 2020. Source: Own elaboration on national ministries of health and statistical agencies datasets

large cluster from the east to Ile de France (the political and economic centre of the country). A distinctive band of high-high clustering is also located in the United Kingdom (in the southeast and the centre of England and Wales) in May.

The geographical patterning of low-low clusters is also broadly consistent over time, with this type of spatial cluster predominantly found in western France, Denmark, eastern Germany, eastern Austria and southern Italy (April and May).

\section{Modelling outcomes}

This section discusses the findings presented in Table 3 for the COVID-19 death rate. We comment only on the results of the SAR model, which, as indicated above, performs better than the OLS and SEM models. These results are robust to the use of inverse squared distance and k-nearest neighbours spatial weight matrices (for $k=3,4,5,10$ ). ${ }^{7}$ Our estimations of the COVID-19 death rates on three different dates provide stable results in the sense that the significant demographic, income and wealth and health care determinants remain the same regardless of the measurement date. The magnitude of the coefficients, however, varies over time. All the significant coefficients on the variables increase over time in absolute value. One notices only two (but essential) differences, which concern the distance to EU targets and the

\footnotetext{
${ }^{7}$ Complete results are available from the authors upon request.
} 


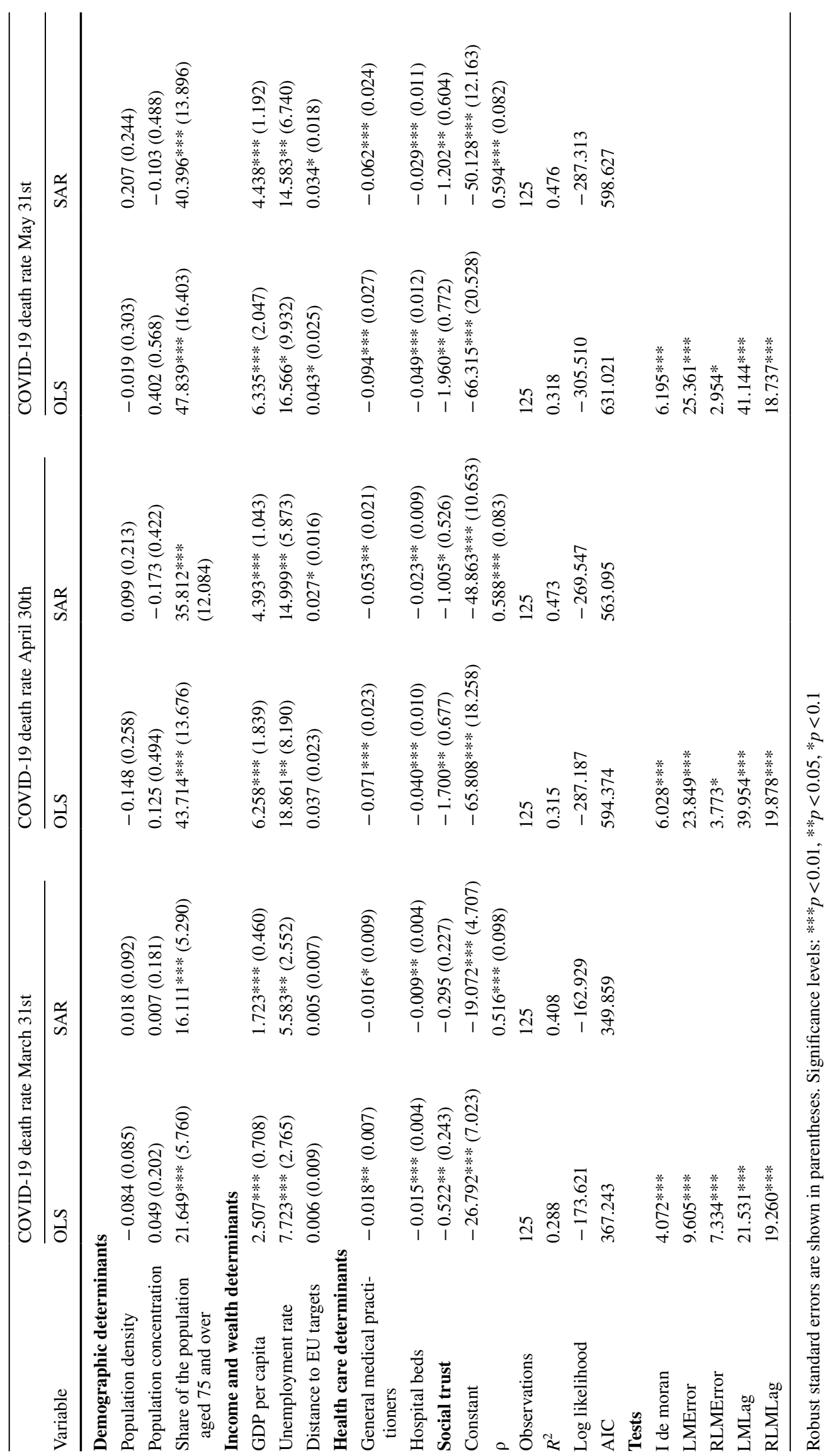


variable social trust. These variables are not significant at the end of March, but their significance and weight increase over time. The results presented in Table 3 are discussed below.

Of the demographic variables, only one is significant. We observe that a higher proportion of people aged 75 or over is related to a higher death rate from COVID-19. This result confirms the risk factor of age frequently mentioned in the literature [66] and the critical role of demographics, particularly how the age structure of a population may help explain differences in fatality rates across regions and how transmission unfolds [8].

All the variables describing income and wealth levels are significant, confirming that COVID-19 is a social disease $[1,51]$. Due to the introduction of three proxies for the economic development level in the regions under review, our findings are more precise than those obtained by Stojkoski et al. [59] in their analysis of differences between countries. They take into account only GDP per capita, a metric for determining a country's economic output per person in that country. It is a widely used indicator of economic performance and a useful measure for making cross-regional comparisons of average living standards and economic wellbeing. GDP per capita also mirrors the ability of a country to intervene in a public health crisis [60]. When Stojkoski and co-authors combine GDP per capita with other demographics and societal characteristics, they conclude that COVID-19 also spreads according to societal characteristics. However, GDP per capita does not take into account socio-economic inequalities in a country. It is complemented by the unemployment rate, whose positive and significant sign confirms the findings in the literature [37], which emphasizes social exclusion and limited access to economic resources resulting from job loss [47]. Additional information on wealth and income is provided by the region's distance to EU targets, a composite index that captures social gaps, on the one hand, and the employment rate on the other hand. Both the unemployment rate and the distance to EU targets are associated with significant positive coefficients, leading us to conclude that more serious social difficulties are more likely to increase the mortality rate due to COVID-19. Thus, our results provide additional evidence on the aggravating role of inequalities and social exclusion in the spread and intensity of epidemics. They also show that the influence of these variables increases as the epidemic becomes more severe.

Health care determinants reflect governmental and regional health spending, proxied by the number of general practitioners and the number of hospital beds. Both are negatively correlated with the COVID-19 death rate, confirming that regions in which the quality of the health system is low are more likely to have a more significant mortality associated with COVID-19. With the need to hospitalize $>15 \%$ of infected patients in intensive care units [52], the effective saturation of hospitals has been a critical issue in the management of the COVID-19 emergency and the death rate across areas [64]. For instance, since 2009, Italy has experienced a $€ 37$ billion cut in healthcare costs and a substantial decrease in its number of hospital beds, which dropped to 3.2 per 1000 inhabitants, compared with a European average of 5 per 1000 inhabitants [15]. Although national, health policies have, however, affected European regions differently. The number of hospital beds tends to be significantly higher in German regions, with 800 beds per 100,000 inhabitants on average. Lower rates are observed in southern Italy, southern Spain, some Greek regions and the UK (less than 250). Our results confirm the literature's findings, which also point out these discrepancies between regions [31]. The literature also highlights the central role of primary care professionals [17] as determinants of mortality.

Finally, our last, but not least relevant, result concerns the negative sign associated with the composite variable "social trust" computed from primary sources provided by the European Social Survey (see Appendix A1 for a complete presentation of this variable). Our findings show that social trust is negatively correlated with COVID-19 death rates.

It is reasonable to consider that social trust acts similarly to institutional trust in that a crisis intensifies the primary trust culture. People with low trust tend to identify negative aspects of ambiguous situations [63], to consider that others do not respect the rules and, thus, to try to bypass them, underestimating the severity of the pandemic. In contrast, in places where a vast majority of citizens exhibit a high level of confidence in others, rules are expected to be respected by others and are indeed respected by everyone.

Our results confirm that an essential aspect of the spread of the pandemic is citizen-to-citizen trust, an intangible asset able to shape the consequences of the COVID-19 phenomenon. Indeed, people's willingness to engage in protective behaviours and respect lockdown rules depends on the belief that others will act in the same way and, broadly speaking, on social capital.

The spread of the virus could thus be more difficult in places where interpersonal relations and social trust are high than in regions characterized by a low level of trust, as already mentioned by Habibov et al. [24].

The relevance of trust for dealing with health emergencies is also linked to the limits of direct enforcement of the required behavioural changes: without the active cooperation of the population, any drastic intervention is doomed to fail because the desired behaviours (e.g., frequently sanitizing one's hands, wearing a facemask and keeping a safe distance from others) cannot be effectively monitored on the required scale and with sufficient frequency [18].

These results on the importance of trust as a protective factor are in line with those of previous studies on other epidemics, e.g. Ebola, showing how people with higher trust 
are more likely to follow the guidelines given by the health authorities [65].

Our findings confirm those of Putnam et al. [49], who conclude that information and political decisions are not enough to ensure the success of sanitary policies. Instead, they recommend mobilizing "social capital" in the community as an informal means of action against the epidemic. This background helps to adapt measures to the current context and to increase their effectiveness.

Our estimations also provide strong evidence of the proximity effect leading to the spread of the coronavirus. Indeed, with a significant $\rho$ parameter ranging between 0.516 and 0.594 , our results suggest that the autoregressive component of the model captures most of the spatial dependence in the data. This result reflects a diffusion effect among the regions located close to each other. The growing value and significance of the parameter estimates indicate that spatial autocorrelation has increased over time, reflecting the polarization of the epidemic in particular clusters.

\section{Conclusion and discussion}

As with any disease, the mortality resulting from COVID19 results from individual characteristics. However, the local economic and social context also matters, as is recalled by the abundant literature [38] that considers regional characteristics to be determinants of regional mortality and may help clarify the regional discrepancies observed since the beginning of the pandemic. This paper sheds light on the spatial heterogeneity in European regions and its persistence during the expansion, peak, and beginning of the decrease of the pandemic. Although some regions were severely hit by the formation of COVID-19 clusters in which the mortality rates were significantly higher than on average, some other regions were spared, composing a belt of low mortality rates mainly located on the eastern and southern fringes of Europe. Our first conclusion is thus that COVID-19 is a global pandemic taking the form of intense local epidemics. In addition to this peculiar spatial distribution of the mortality rates, our results lead us to conclude that if some particular events occur (football matches, a meeting of the faithful of a church, the arrival of infected people coming from already affected non-European countries, etc.), the resulting spread of the epidemic can be explained by a mix of factors describing the socioeconomic context. In addition to the classical demographic indicators, we found that income and wealth, on the one hand, and public health policies, on the other hand, were tangible elements enabling us to explain the local differences observed. In addition to these monetary or purely quantitative aspects, the introduction of an intangible asset named social trust permitted us to enrich the analysis by introducing culture and interpersonal relationships. They are shown to influence the mortality rate from COVID-19 and that their role increased over the period studied. According to our findings, compliance with sanitation rules imposed to control the pandemic and to flatten the peak of infections in order to limit congestion in hospitals depend on trust that others will respect those rules. This cultural aspect should thus be considered when deciding on the implementation of sanitation rules because, beyond their theoretically expected effects, their real effects depend on their actual use resulting from social trust.

Our research underlines the importance of regional differences in mortality rates and their origin during the pandemic. This contribution could be of interest to policymakers and health agencies. The regional dimension of public health policies, even in countries where this policy is centrally managed, such as in France, results in the requirement of efforts to disentangle the spatial aspects of epidemics to design policies adapted to the context in which such epidemics occur. Strengthening this local dimension is essential for two main reasons. First, COVID-19, unlike other epidemics, such as the flu, does not spread uniformly across regions but tends to remain clustered. Second, the high rate of contagion of this disease requires a rapid detection of patients zero in order to almost immediately adopt the necessary sanitation rules that help to prevent the spread of cases. Moreover, the proximity between policymakers and citizens helps the former know the culture, social norms and trust better. Consequently, measures adopted to reduce the severity of epidemics could be more effective when defined as closely as possible to the field.

To expand our conceptual framework, these exploratory and quantitative analyses should be complemented by more indepth investigations. Future research should pay more attention to controlling the proportion of false declarations of significance among those individual deviations from null hypotheses considered to be significant. The recent studies have shown a significant gain in the identification of meaningful clusters when controlling for the FDR [9] in comparison to more conservative approaches, such as Bonferroni and Sidak corrections. An additional shortcoming that should be addressed is the choice of the level of aggregation. This is of paramount importance in any spatial econometric analysis. This issue refers to the modifiable areal unit problem (MAUP) introduced by Openshaw et al. [45], a term used to describe the influence of the spatial breakdown on the results of statistical processing or modelling. More precisely, the irregular forms and limits of administrative levels that do not necessarily reflect the reality of the spatial distributions studied are an obstacle to the comparability of irregularly distributed spatial units. Some geographers recommend adopting a multiscale approach to study the multiplicity of spatial aspects within a single phenomenon. 


\section{Appendix}

See Tables 4 and 5 .
The composite measure is constructed from individual perceptions using factor analysis. Following the Kaiser criterion, which retains the principal components for which

Table 4 Correlation matrix

(1)

(2)

(3)

$\begin{array}{cc}1.000 & \\ 0.357 * * * & 1.000 \\ -0.477 * * * & -0.234 * * *\end{array}$
(4) GDP per capita
(5) Unemployment rate
(6) Distance to EU targets
(7) General Medical Practitioners
(8) Hospital beds
(9) Social trust

and over

(1) Population density

\begin{tabular}{|c|c|c|c|c|c|c|c|}
\hline $0.427 * * *$ & 0.039 & $-0.294 * * *$ & 1.000 & & & & \\
\hline 0.027 & 0.094 & -0.084 & $-0.513 * * *$ & 1.000 & & & \\
\hline $0.214 * *$ & $0.175^{*}$ & $-0.242 * * *$ & $0.567 * * *$ & $-0.583 * * *$ & 1.000 & & \\
\hline $0.227 * *$ & -0.109 & $0.179 * *$ & $0.214 * *$ & $0.215^{* *}$ & -0.075 & 1.000 & \\
\hline-0.107 & $-0.151 *$ & $0.342 * * *$ & 0.138 & $-0.252 * * *$ & $0.195 * *$ & $0.288 * * * 1.000$ & \\
\hline 0.067 & -0.087 & $-0.259 * * *$ & $0.459 * * *$ & $-0.598 * * *$ & $0.625 * * *$ & $-0.145 \quad 0.020$ & 1.000 \\
\hline
\end{tabular}

Table 5 Summary statistics

\begin{tabular}{lrrrrr}
\hline Variable & Obs & Mean & Std.Dev & Min & Max \\
\hline COVID death rate on March 31st & 125 & 0.73 & 1.15 & 0.00 & 7.16 \\
COVID death rate on April 30th & 125 & 2.67 & 2.92 & 0.01 & 13.69 \\
COVID death rate on May 31st & 125 & 3.28 & 3.39 & 0.01 & 16.01 \\
Population density & 125 & 5.21 & 1.17 & 3.11 & 8.93 \\
Population concentration & 125 & 0.45 & 0.50 & 0.00 & 1.00 \\
Share of the population aged 75 and over & 125 & 0.10 & 0.02 & 0.05 & 0.16 \\
GDP per capita & 125 & 10.33 & 0.28 & 9.76 & 11.30 \\
Unemployment rate & 125 & 0.08 & 0.05 & 0.02 & 0.29 \\
Distance to EU targets & 125 & 76.97 & 17.62 & 35.09 & 132.14 \\
General Medical Practitioners & 125 & 37.01 & 11.67 & 6.26 & 78.63 \\
Hospital beds & 125 & 44.72 & 23.88 & 9.46 & 128.63 \\
Social trust & 125 & -0.12 & 0.52 & -1.92 & 1.11 \\
\hline
\end{tabular}

\section{A1. Measuring social trust}

To analyse social trust or, more generally, social capital, it is now common to use a composite measure that combines a large array of indicators related to cooperative norms and the density of associational networks. In this study, social trust is calculated following the methodology used in Parente [46].

The construction of this variable is as follows. We use three questions from the European Social Survey relative to social trust (A4, A5 and A6). A4-A6's numeric answers range along an 11-point scale, where 0 means one cannot be too careful/people will try to take advantage of you/people are mostly looking out for themselves, and 10 means that most people can be trusted/they try to be fair/they try to be helpful. the value is higher than or equal to 1 , we keep one factorial plan. This plan explains $67 \%$ of the variance in the answers. Hence, the final index of social trust is calculated as the average of our composite measure at the regional level. A positive score indicates a high level of trust, fairness and helpfulness, and a negative score indicates a low level of social trust in the region.

\begin{tabular}{lccl}
\hline & Comp1 & Comp2 & Comp3 \\
\hline Eigenvalues & 2.01 & 0.55 & 0.44 \\
Explained variance (\%) & $66.99 \%$ & $18.26 \%$ & $14.75 \%$ \\
Cumulative variance (\%) & $66.99 \%$ & $85.25 \%$ & $100 \%$ \\
\hline
\end{tabular}




\section{References}

1. Amdaoud, M., Arcuri, G. Levratto, N.: COVID-19: analyse spatiale de l'influence des facteurs socio-économiques sur la prévalence et les conséquences de l'épidémie dans les départements français, EconomiX Working Papers 2020-4, University of Paris Nanterre, EconomiX (2020)

2. Anselin, L.: Local indicators of spatial association-LISA. Geogr. Anal. 27, 93-115 (1995)

3. Anselin, L., Bera, A.K., Florax, R., Yoon, M.J.: Simple diagnostic tests for spatial dependence. Reg. Sci. Urban Econ. 26(1), 77-104 (1996)

4. Anselin, L.: Spatial econometrics: methods and models. Kluwer, Dordrecht (1988)

5. Ascani, A., Faggian, A., Montresor, S.: The geography of COVID-19 and the structure of local economies: the case of Italy. J. Reg. Sci. (2020). https://doi.org/10.1111/jors.12510

6. Barrios, J.M., Benmelech, E., Hochberg, Y.V., Sapienza, P., Zingales, L.: Civic capital and social distancing during the Covid19 pandemic. J. Public Econ. 193, 104310 (2021). https://doi. org/10.1016/j.jpubeco.2020.104310

7. Bayer, C., Kuhn , M.: Intergenerational ties and case fatality rates: a cross country analysis. CEPR Discussion Paper no. 14519 (2020)

8. Beam Dowd, J., Andriano, L., Brazel, D.M., Rotondi, V., Block, P., Ding, X., Liu, Y., Mills, M.C.: Demographic science aids in understanding the spread and fatality rates of COVID-19. Proc. Natl. Acad. Sci. USA. 117(18), 9696-9698 (2020). https://doi. org/10.1073/pnas.2004911117

9. Benjamini, Y., Hochberg, Y.: Controlling the false discovery rate: a practical and powerful approach to multiple testing. J. R. Stat. Soc. B57(1), 289-300 (1995)

10. Borjas, G.J.: Demographic determinants of testing incidence and COVID-19 infections in New York City neighbourhoods. COVID Economics, Vetted and Real-Time Papers (2020)

11. Bourdin, S., Ludovic, J., Nadou, F., Noiret, G.: Does lockdown work? A spatial analysis of the spread and concentration of COVID-19 in Italy. Reg. Stud. (2021). https://doi.org/10.1080/ 00343404.2021.1887471

12. Cambois, E., Jusot, F.: Ampleur, tendance et causes des inégalités sociales de santé et de mortalité en Europe : une revue des études comparatives. Bulletin épidémiologique hebdomadaire. 2-3 (2007)

13. Chuang, Y.-C., Huang, Y.-L., Tseng, K.-C., Yen, C.-H., Yang, L.-H.: Social capital and health protective behavior intentions in an influenza pandemic. PLoS ONE 10(4), e0122970 (2015). https://doi.org/10.1371/journal.pone.0122970

14. Connolly, C., Keil, R., Ali, S.H.: Extended urbanisation and the spatialities of infectious disease: demographic change, infrastructure and governance. Urban Stud. 10(1177/0042098020910873), $11(2020)$

15. De Leverano, A.: Post COVID EU Recovery: is there room to invest in Healthcare? ZEW-Kurzexpertise Nr. 20-14, Mannheim (2020)

16. Du, Y., Tu, L., Zhu, P., Mu, M., Wang, R., Yang, P., Wang, X., Hu, C., Ping, R., Hu, P., Li, T., Cao, F., Chang, C., Hu, Q., Jin, Y., Xu, G.: Clinical features of 85 fatal cases of COVID-19 from Wuhan. A retrospective observational study. Am. J. Respir. Crit. Care Med. 201(11), 1372-1379 (2020). https://doi.org/10.1164/ rccm.202003-0543OC

17. Dunlop, C., Howe, A., Li, D., Allen, L.N.: The coronavirus outbreak: the central role of primary care in emergency preparedness and response. BJGP Open. 4, 1 (2020). https://doi.org/10.3399/ bjgpopen20X101041
18. Falcone, R., Colì, E., Felletti, S., Sapienza, A., Castelfranchi, C., Paglieri, F.: All we need is trust: how the COVID-19 outbreak reconfigured trust in Italian Public Institutions. Front. Psychol. 11, 561747 (2020). https://doi.org/10.3389/fpsyg.2020.561747

19. Fogli, A., Veldkamp, L.: Germs, Social Networks, and Growth, Staff Report 572, Federal Reserve Bank of Minneapolis (2018)

20. Frohlich, N., Mustard, C.: A regional comparison of socioeconomic and health indices in a Canadian province. Soc. Sci. Med. 42(9), 1273-1281 (1996)

21. Geronimus, A.T., Bound, J., Waidmann, T.A.: Poverty, time, and place: variation in excess mortality across selected US populations, 1980-1990. J. Epidemiol. Commun. Health. 53(6), 325-334 (1999)

22. Gizelis, T.-I., Karim, S., Østby, G., Urdal, H.: Maternal health care in the time of Ebola: a mixed-method exploration of the impact of the epidemic on delivery services in monrovia. World Dev. 98, 169-178 (2017)

23. Guillain, R., Le Gallo, J.: Agglomeration and dispersion of economic activities in and around Paris: an exploratory spatial data analysis. Environ. Plan. B: Plan. Design. 37(6), 961-981 (2010)

24. Habibov, N., Cheung, A., Auchynnikava, A.: Does social trust increase willingness to pay taxes to improve public healthcare? Cross-sectional cross-country instrumental variable analysis. Soc. Sci. Med. 189, 25-34 (2017)

25. Hogan, D.R., Stevens, G.A., Hosseinpoor, A.R., Boerma, T.: Monitoring universal health coverage within the sustainable development goals: development and baseline data for an index of essential health services. Lancet Glob. Health. 6(2), 152-168 (2018)

26. Hosseini, P., Sokolow, S.H., Vandegrift, K.J., Kilpatrick, A.M., Daszak, P.: Predictive power of air travel and socio-economic data for early pandemic spread. PLoS ONE 5(9), e12763 (2010). https://doi.org/10.1371/journal.pone.0012763

27. Hu, Y., Goldman, N.: Mortality differentials by marital status: an international comparison. Demography 27, 233-250 (1990)

28. Kang, D., Choi, H., Kim, J.H., Choi, J.: Spatial epidemic dynamics of the COVID-19 outbreak in China. Int. J. Infect. Dis. 94, 96-102 (2020). https://doi.org/10.1016/j.ijid.2020.03.076

29. Kauhl, B., Heil, J., Hoebe, C.J.P.A., Schweikart, J., Krafft, T., Dukers-Muijrers, N.H.T.M.: The spatial distribution of hepatitis $\mathrm{C}$ virus infections and associated determinants-an application of a geographically weighted Poisson regression for evidence-based screening interventions in hotspots. PLoS ONE 10(9), e0135656e0135656 (2015). https://doi.org/10.1371/journal.pone.0135656

30. Koh, H.K., Cadigan, R.O.: Disaster preparedness and social capital. In: Kawachi, I., Subramanian, S., Kim, D. (eds.) Social capital and health, pp. 273-285. Springer, New York, NY (2008)

31. Krenz, A., Strulik, H.: The benefits of remoteness: Digital mobility data, regional road infrastructure, and COVID-19 infections. CEGE Discussion Papers, No. 396 (2020). Available at: https:// www.econstor.eu/bitstream/10419/219321/1/1700585576.pdf. Accessed 26 June 2020

32. Le Gallo, J.: Econométrie spatiale : l'autocorrélation spatiale dans les modèles de régression linéaire. Eco. Prév. 4, 139-157 (2002)

33. Lin, Q., Chiu, A.P., Zhao, S., He, D.: Modeling the spread of Middle East respiratory syndrome coronavirus in Saudi Arabia. Stat. Methods Med. Res. 27(7), 1968-1978 (2018)

34. Linard, C., Lamarque, P., Heyman, P., Ducoffre, G., Luyasu, V., Tersago, K., Vanwambeke, S.O., Lambin, E.F.: Determinants of the geographic distribution of Puumala virus and Lyme borreliosis infections in Belgium. Int. J. Health Geogr. 6(1), 15 (2007). https://doi.org/10.1186/1476-072X-6-15

35. Link, B.G., Phelan, J.C.: Social conditions as fundamental causes of disease. Journal of Health and Social Behaviour. Numéro special "Forty Years of Medical Sociology: The State of the Art and Directions for the Future", 80-94 (1995) 
36. Markowitz, S., Nesson, E., Robinson, J.: The effects of employment on influenza rates. Eon. Hum. Biol. 34, 286-295 (2019)

37. Mathers, C., Scholfield, D.: The health consequences of unemployment: the evidence. Med. J. Aust. 168, 178-182 (1998)

38. McCoy, D.: Hat exactly is the government's coronavirus strategy? Queen Mary University of London (2020). https://www.qmul.ac. uk/media/news/2020/pr/what-exactly-is-the-governments-coron avirus-strategy.html. Accessed 25 May 2020

39. Mollalo, A., Vahedi, B., Rivera, K.M.: GIS-based spatial modeling of COVID-19 incidence rate in the continental United States. Sci. Total Environ. 728, 138884 (2020). https://doi.org/10.1016/j. scitotenv.2020.138884

40. Mongey, S., Pilossoph, L., Weinberg, A.: Which workers bear the burden of social distancing policies? CEPR Press. 12(1), 69-86 (2020)

41. Moran, P.A.: Notes on continuous stochastic phenomena. Biometrika 37, 17-23 (1950)

42. OECD: The territorial impact of COVID-19: Managing the crisis across levels of government (2020) http://www.oecd.org/coronavirus/policy-responses/the-territorial-impact-of-COVID-19-manag ing-the-crisis-across-levels-of-government-d3e $314 \mathrm{e} 1 /$. Accessed 25 June 2020

43. Olson, N.A., Davidow, A.L., Winston, C.A., Chen, M.P., Gazmararian, J.A., Katz, D.J.: A national study of socioeconomic status and tuberculosis rates by country of birth, United States, 1996-2005. BMC Public Health 12, 365 (2012). https://doi.org/ 10.1186/1471-2458-12-365

44. Onder, G., Resa, G., Brusaferro, S.: Case-fatality rate and characteristics of patients dying in relation to COVID-19 in Italy. JAMA (2020). https://doi.org/10.1001/jama.2020.4683

45. Openshaw, S.: The modifiable areal unit problem. T. CATMOG 38. GeoBooks, Norwich, Englan (1984)

46. Parente, F.: Inequality and social capital in the EU regions: a multidimensional analysis. Reg. Stud. Reg. Sci. 6(1), 1-24 (2019). https://doi.org/10.1080/21681376.2018.1558105

47. Pohlan, L.: Unemployment and social exclusion. J. Econ. Behav. Organ. 164, 273-299 (2019)

48. Prior, L., Manley, D., Sabel, C.E.: Biosocial health geography: new 'exposomic' geographies of health and place. Prog. Hum. Geogr. 43(3), 531-552 (2018)

49. Putnam, R.D., Leonardi, R., Nanetti, R.Y.: Making democracy work: civic traditions in modern Italy. Princeton University Press, New Jersey (1993)

50. Putnam, R.D.: Bowling alone: America's declining social capital. J Democracy. 6, 65-78 (1995)

51. Qiu, Y., Chen, X., Shi, W.: Impacts of social and economic factors on the transmission of coronavirus disease 2019(COVID19) in China. J. Popul. Econ (2020). https://doi.org/10.1007/ s00148-020-00778-2

52. Qiu, H., Tong, Z., Ma, P., Hu, M., Peng, Z., Wu, W., Du, B.: Intensive care during the coronavirus epidemic. Intensive Care Med. 46, 576-578 (2020). https://doi.org/10.1007/s00134-020-05966-y

53. Sannigrahi, S., Pilla, F., Basu, B., Basu, A.S.: The overall mortality caused by COVID-19 in the European region is highly associated with demographic composition: A spatial regression-based approach. arXiv:2005.04029 [q-bio] (2020)

54. Schmitt-Grohé, S., Teoh, K., Uribe, M.: COVID-19: Testing Inequality in New York City. COVID Economics. 8, 27-43 (2020)

55. Scott, A., Coote, W.: Whither Divisions of General Practice? An empirical and policy analysis of the impact of Divisions within the Australian health care system. Med. J. Aust. 187(2), 95-99 (2007). https://doi.org/10.5694/j.1326-5377.2007.tb01149.x

56. Scott, R., O'Brien, R., Fulcher, G., Pardy, C., D'Emden, M., Tse, D., Taskinen, M.R., Ehnholm, C., Keech, A.: Effects of fenofibrate treatment on cardiovascular disease risk in 9,795 individuals with type 2 diabetes and various components of the metabolic syndrome: the Fenofibrate Intervention and Event Lowering in Diabetes (FIELD) study. Diabetes Care 32(3), 493-498 (2009). https:// doi.org/10.2337/dc08-1543

57. Souris, M., Gonzalez, J.P., Shanmugasundaram, J., Corvest, V., Kittayapong, P.: Retrospective space-time analysis of H5N1 Avian Influenza emergence in Thailand. Int. J. Health Geogr. 9, 3 (2010)

58. Stanturf, J.A., Goodrick, S.L., Warren, M.L., Jr., Charnley, S., Stegall, C.M.: Social vulnerability and Ebola virus disease in rural liberia. PLoS ONE 10(9), e0137208 (2015). https://doi.org/10. 1371/journal.pone. 0137208

59. Stojkoski, V., Utkovski, Z., Jolakoski, P., Tevdovski, D., Kocarev, L.: The socio-economic determinants of the coronavirus disease (COVID-19) pandemic. arXiv:2004.07947 [physics.soc-ph] (2020)

60. Strauss, J., Duncan, T.: Health, nutrition, and economic development. J. Econ. Lit. 36(2), 766-817 (1998)

61. Talavera, A., Perez, E.M.: Is cholera disease associated with poverty? J. Infect. Dev. Ctries 1-3(6), 408-411 (2009)

62. Van Bavel, J.J., Baicker, K., Boggio, P.S., Capraro, V., Cichocka, A., Cikara, M., et al.: Using social and behavioural science to support COVID-19 pandemic response. Nat. Hum. Behav. 4, 460-471 (2020)

63. Vaughan, E., Tinker, T.: Effective health risk communication about pandemic influenza for vulnerable populations. Am J Public Health 99(Suppl 2), S324-332 (2009). https://doi.org/10.2105/ ajph.2009.162537

64. Vinci, D.L., Polidori, C., Polidori, P.: The healthcare and pharmaceutical vulnerability emerging from the new Coronavirus outbreak. Eur. J. Hosp. Pharm. 27(3), 129-130 (2020). https:// doi.org/10.1136/ejhpharm-2020-002278

65. Vinck, P., Pham, P., Bindu, K., Bedford, J., Nilles, E.: Institutional trust and misinformation in the response to the 2018-19 Ebola outbreak in North Kivu. DR Congo: a population-based survey. Lancet Infect. Dis. 19, 529-536 (2019). https://doi.org/10.1016/ s1473-3099(19)30063-5

66. Wilson, N., Kvalsvig, A., Barnard, L.T., Baker, M.G.: Case-fatality risk estimates for COVID-19 calculated by using a lag time for fatality. Emerg. Infect. Dis. 26(6), 1339-1441 (2020). https://doi. org/10.3201/eid2606.200320

67. Wood, E., Chan, K., Montaner, J.S., Schechter, M.T., Tyndall, M., O'Shaughnessy, M.V., Hogg, R.S.: The end of the line: has rapid transit contributed to the spatial diffusion of HIV in one of Canada's largest metropolitan areas? Soc. Sci. Med. 51(5), 741-748 (2000)

68. Wu, Z., Mcgoogan, J.M.: Characteristics of and Important Lessons from the Coronavirus Disease 2019 (COVID-19) Outbreak in China-summary of a Report of 72314 Cases from the Chinese Center for Disease Control and Prevention. JAMA 323(13), 1239-1242 (2020). https://doi.org/10.1001/jama.2020.2648

69. Zanakis, S.H., Alvarez, C., Li, V.: Socio-economic determinants of HIV/AIDS pandemic and nations efficiencies. Eur. J. Oper. Res. 176(3), 1811-1838 (2007)

70. Zhu, G., Xiao, J., Liu, T., Zhang, B., Hao, Y., Ma, W.: Spatiotemporal analysis of the dengue outbreak in Guangdong Province, China. BMC Infect. Dis. 19(1), 493 (2019)

Publisher's Note Springer Nature remains neutral with regard to jurisdictional claims in published maps and institutional affiliations. 